\title{
Antibiofilm activity of biogenic copper and zinc oxide nanoparticles-antimicrobials collegiate against multiple drug resistant bacteria: a nanoscale approach
}

\author{
C. Ashajyothi ${ }^{1}$ K. Handral Harish ${ }^{2} \cdot$ Nileshkumar Dubey $^{2} \cdot$ R. Kelmani Chandrakanth ${ }^{1}$
}

Received: 27 July 2016/ Accepted: 20 September 2016/Published online: 30 September 2016

(C) The Author(s) 2016. This article is published with open access at Springerlink.com

\begin{abstract}
The synthesis of biogenic nanoparticles from non-chemical resources has increased the drive toward understanding infection biology. Accordingly, we aimed to address the symbiotic antibiofilm effect of biogenic copper and zinc oxide nanoparticles with antimicrobials against multidrug resistant (MDR) pathogens. The minimum inhibitory concentration (MIC) of copper nanoparticles (CuNPs) and zinc oxide nanoparticles (ZnONPs) at the range from 2 to $128 \mu \mathrm{g} / \mathrm{ml}$ was calculated against Grampositive and Gram-negative pathogenic bacteria using a broth dilution method. Both nanoparticles have prime antibacterial activity compared with standard antibiotics (excluding against P.aeruginosa MTCC 741). A qualitative assessment of biofilm formation and collegial effect was performed using a modified test tube and the microtiter plate-based method by measuring the optical density and time kill of nanoparticles. The results demonstrated efficient antibiofilm activity of CuNPs in its lowest concentration than ZnONPs and antibiotics itself. In addition, significant enhancing antibiofilm effect was also shown by CuNPs in the presence of third generation antibiotics against Gram-negative and Gram-positive bacteria. A scanning electron microscopy (SEM) analysis was used to investigate the effect of the nanoparticles on morphological changes of Staphylococcus aureus. Current data highlights,
\end{abstract}

R. Kelmani Chandrakanth

ckelmani@gmail.com

1 Department of Biotechnology, Gulbarga University, Gulbarga 585106, Karnataka, India

2 Oral Sciences Disciplines, Faculty of Dentistry, National University of Singapore, Singapore 117510, Singapore biogenic CuNPs and ZnONPs could be used as an adjuvant for antibiotics in the treatment of bacterial infections.

Keywords Biogenic nanoparticles - Test tube method . Microtiter plate method - Scanning electron microscopy . Antibiofilm activity

\section{Introduction}

Biofilms are complex communities of microorganisms that show resistance to the action of antibiotics and the human immune system, due to their resistant nature and stability $[1,2]$. Biofilm infections are difficult to eradicate, especially in the case of multidrug resistant pathogens [3]. Recently, the number of infections associated with budding antibiotic resistant bacteria has increased [4]. Remarkably, bacteria-host interactions could raise the rate of infections in which pathogens rapidly kill the host. Both Gram-positive and Gram-negative bacteria can form a biofilm on medical devices, such as catheters, mechanical heart valves, and prosthetic joints [5]. Biofilm-related diseases are typically persistent infections characterized by slow development, and these diseases have an ability to resist both a host's immune system and a transient response to antimicrobial therapy [6].

Staphylococcus aureus, Staphylococcus epidermidis, Escherichia coli, Klebsiella pneumonia, and Pseudomonas aeruginosa are the most common biofilm forming bacteria causing human disease, such as infection lesion in endocarditis, cystic fibrosis, and otitis media with effusion [7]. Biofilms have also been identified in most indwelling medical device infections and in biliary tract infections, periodontitis, and ophthalmic infections [8]. 
Nowadays, treatment of biofilms with antibiotics has been shown to be ineffective, since many agents fail to reach the target cells embedded deep inside the biofilm matrix. An alternative approach is needed to control the diseases involving biofilms [9].

Various methods, such as use of bacteriophages and designing of semi-synthetic analogs of natural products to prevent bacterial biofilms, were considered to address the ineffectiveness of antibiotics. In contrast to above-revealed conventional methods, the nanotechnology-based approach is one such efficient approach to combat biofilm formation. The use of nanoparticles has been considered as a feasible solution to stop infectious diseases due to their antimicrobial properties. There are numerous reports explaining the multifaceted potential of nanoparticles as antimicrobial agents. The ability of metals to target multiple sites in an organism makes them superior to conventional antibiotics [10].

Currently, nanoparticles are considered as active and safe drugs to boost the antibacterial activity of conventional antibiotics, through exploit these new antimicrobials effectively with important antibiotics in synergistic combination therapy against pathogenic microorganism [11]. The combination of nanoparticles with existing antibiotics seems to be very enthralling option by combining the two treatment modalities. Recent studies have revealed that the combining nanoparticle with antibiotics not only reduces the toxicity of both agents toward human cells by decreasing the requirement for high dosages but also enhances and restores their bactericidal properties [12].

Among the metal nanoparticles, CuNPs are superconductive, easily available, and cost-effective metal well known for its variety of applications. CuNPs are also considered as an effective nanoparticle against plant and animal pathogens [13]. Most pathogens, including strains of Clostridium difficile, Salmonella enterica, Campylobacter jejuni, Escherichia coli 0157:H7, Pseudomonas aeruginosa, Enterobacter aerogenes, Staphylococcus aureus, methicillin-resistant $S$. aureus (MRSA), and vancomycin-resistant Enterococcus (VRE), are killed when exposed to the surfaces of copper and copper alloys have been reported by Wilks et al. 2005 and Casey et al. 2010 in their study $[14,15]$.

According to Borkow et al. (2010) to prevent the bacterial contamination on medical devices, CuNPs have also been used as antimicrobial coating agents [16]. Inspite of their bioactivity, the antibiofilm potential of CuNPs is rarely explored [17]. Only a few reports are published in the last year on, the use of copper-containing nanoparticles in the treatment of biofilms $[9,18]$.
According to Begum et al. (2009) and Guy Applerot et al. (2012), using the inorganic metal oxide nanoparticles, such as $\mathrm{TiO}_{2}, \mathrm{ZnO}, \mathrm{MgO}$, and $\mathrm{CaO}$ as an antibacterial agent, has a major advantages due to its stability under harsh process conditions but also generally regarded as safe materials to human beings and animals compared to organic materials such as conventional antibiotics $[19,20]$. Studies on antibacterial activity among the various metal oxides nanoparticles, zinc oxide nanoparticles, have been found to be highly toxic. Many studies have shown that selective toxic nature of ZnONPs toward bacteria shows the minimal effect on human cells, which is suggested their potential uses in agricultural, food industries, diagnostics, surgical devices, and nanomedicine-based antimicrobial agents [21-24]. Among the several metal oxide nanoparticles, ZnONPs are emerged as booming nanoparticle due to their attractive characteristics and ideal properties in various biomedical applications.

The synergistic activity of ZnONPs with more than 25 different antibiotics against $S$. aureus and E. coli. concludes that ZnONPs can enhance antibacterial activities of penicillins, cephalosporins, aminoglycosides, glycopeptides, macrolides, lincosamides, gentamicin, clarithromycin, ofloxacin, and ceftriaxone and tetracycline $[25,26]$.

Our objective in this investigation is mainly focused on use of biologically synthesized CuNPs and ZnONPs to probe the antibiofilm activity of antimicrobials against the panel of Gram-negative and Gram-positive human pathogens.

\section{Materials and method}

\section{Biogenic metal nanoparticles}

Biogenic nanoparticles: copper (CuNPs) and zinc oxide nanoparticles (ZnONPs) were biologically synthesized from non-pathogenic Enterococcus faecalis by extracellular enzymatic method. Organism was obtained from Medical Biotechnology and Phage Therapy Laboratory (MBPT), Department of Biotechnology, Gulbarga University, Gulbarga.

Enterococcus faecalis culture was inoculated in sterile Luria-Bertani broth (HiMedia, Mumbai, India) and incubated at $37{ }^{\circ} \mathrm{C}$ for $72 \mathrm{~h}$. Culture was centrifuged at $10,000 \mathrm{rpm}$ for $10-15 \mathrm{~min}$ to separate supernatant from pellet. The bacterial supernatant was added separately to the reaction vessels' containing $100 \mathrm{mM}(\mathrm{v} / \mathrm{v})$ copper sulfate $\left(\mathrm{CuSO}_{4}\right.$, HiMedia, Mumbai, India) and zinc sulfate 
( $\mathrm{ZnSO}_{4} \cdot 7 \mathrm{H}_{2} \mathrm{O}$, HiMedia, Mumbai, India), and controls (only with bacterial supernatant) are maintained separately to each reaction. The reaction was carried out for $24 \mathrm{~h}$, at $37^{\circ} \mathrm{C}, \mathrm{pH}: 7$ in rotary shaker at $120 \mathrm{rpm}$ in dark condition $[27,28]$. Furthermore, morphology and crystalline nature of nanoparticles were confirmed and characterized through TEM (Tecnai 20 G2, CSIR-CECRI, Karaikudi, India) and XRD (PW3040/60 X'pert PRO, CSIR-CECRI, Karaikudi, India) analysis.

\section{Collection of bacterial strains}

Clinical isolates, E. coli 03, K. Pneumonia 125, methicillinresistant $S$. aureus 20 (MRSA) were taken from stock cultures of the Medical Biotechnology and Phage Therapy Laboratory (MBPT), Department of Biotechnology, Gulbarga University,
Gulbarga. Standard MTCC cultures, E. coli MTCC 9537, $K$. pneumonia MTCC 109, S. aureus MTCC 96, P. Aeruginosa MTCC 741, S. flexneri MTCC 1457, and E. faecalis NCIM 5025 (Microbial Type Culture Collection and Gene Bank, Chandigarh, India) were stored in Luria-Bertani broth cultures with sterile glycerol at $-20{ }^{\circ} \mathrm{C}(20 \%$, v/v) for further studies.

\section{Minimum inhibitory concentration (MIC) of CuNPs, ZnONPs, and antibiotics}

Minimal inhibitory concentration (MIC) was defined as the lowest concentration of an antimicrobial agent that is needed to inhibit the growth of a microorganism after $24 \mathrm{~h}$ of incubation. The CLSI 2012 M100-S22 practice was implemented to determine the MIC and to assess the

Table 1 Concentrations of CuNPs, ZnONPs, and antibiotics used against different pathogenic bacteria

\begin{tabular}{lllll}
\hline Pathogenic bacteria & CuNPs $(\mu \mathrm{g} / \mathrm{ml})$ & ZnONPs $(\mu \mathrm{g} / \mathrm{ml})$ & Antibiotics $(\mu \mathrm{g} / \mathrm{ml})$ & \\
\hline E. coli 03 & 10 & 10 & Ceftriaxone & 12 \\
E.coliMTCC 9537 & 12 & 16 & Ceftriaxone & 12 \\
K.pneumonia 125 & 18 & 08 & Ceftazidime & 14 \\
K.pneumonia MTCC 109 & 10 & 12 & Ceftazidime & 14 \\
S. aureus 20 & 16 & 16 & Gentamicin & 10 \\
S.aureus MTCC 96 & 20 & 18 & Gentamicin & 10 \\
E.faecalis NCIM 5025 & 20 & 18 & Gentamicin & 10 \\
P.aeruginosa MTCC 741 & 64 & 64 & Ceftazidime & 14 \\
S.flexneri MTCC 1457 & 12 & 10 & Ceftazidime & 14 \\
\hline
\end{tabular}

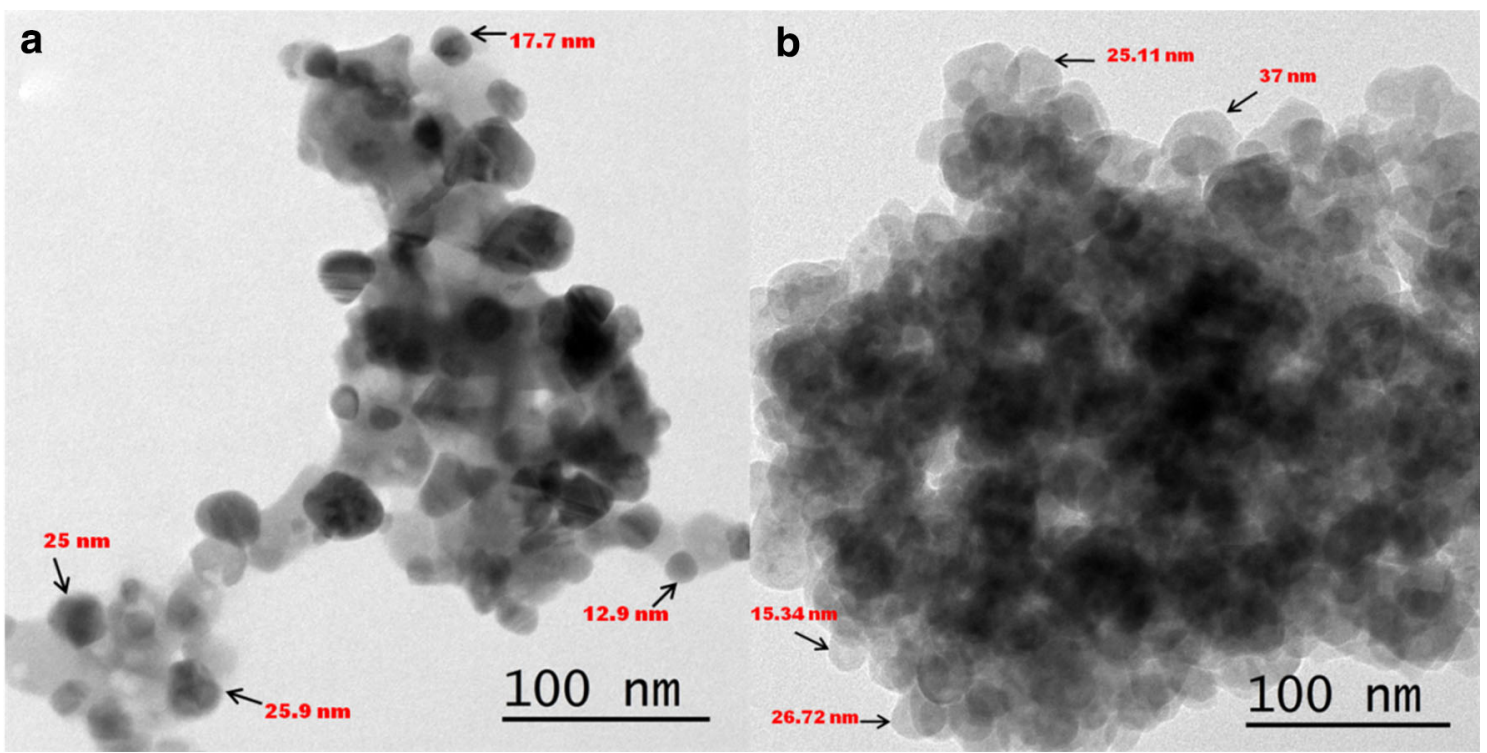

Fig. 1 TEM images of biogenic CuNPs (a) and ZnONPs (b) synthesized from Gram-positive non-pathogenic bacterium Enterococcus faecalis 

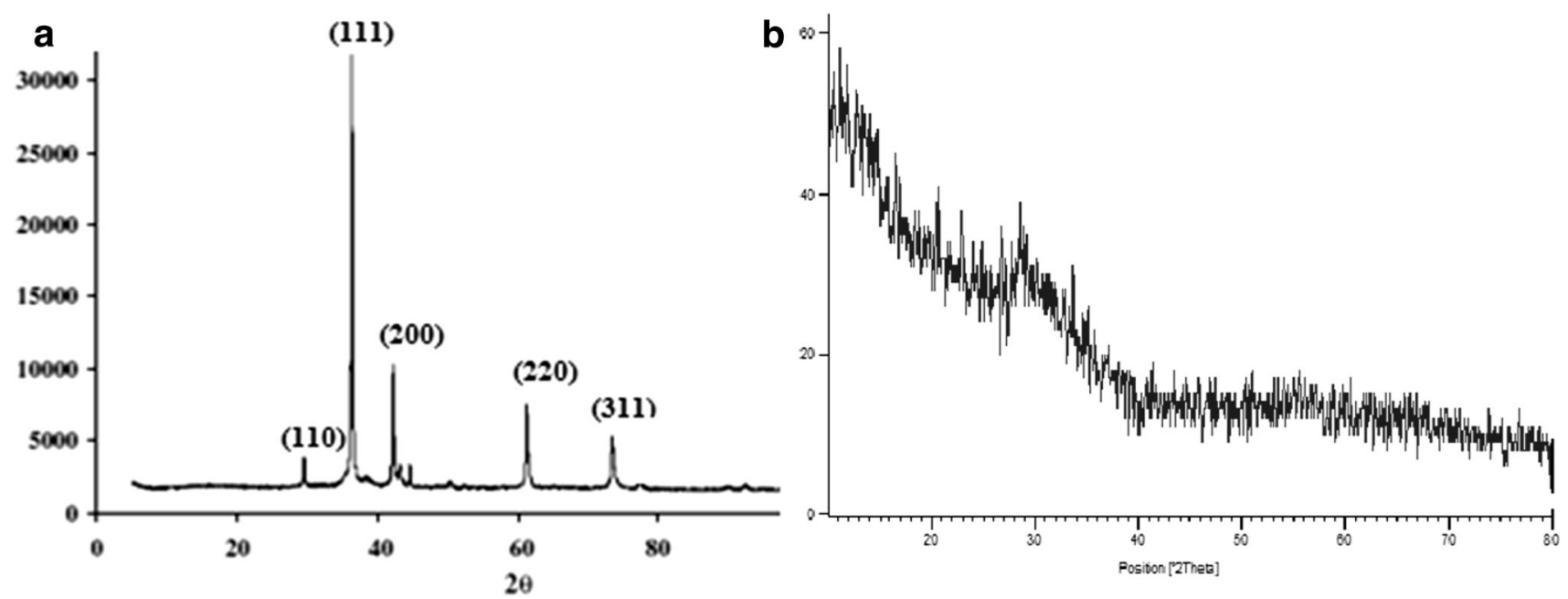

Fig. 2 XRD pattern of biogenic CuNPs (a) and ZnONPs (b)

Table 2 MIC levels of CuNPs and ZnONPs nanoparticles and antibiotics in different pathogenic bacteria

\begin{tabular}{lllll}
\hline Type of pathogen & Pathogenic bacteria & $\begin{array}{l}\text { MIC level of } \\
\text { CuNPs }(\mu \mathrm{g} / \mathrm{ml})\end{array}$ & $\begin{array}{l}\text { MIC level of ZnONPs } \\
(\mu \mathrm{g} / \mathrm{ml})\end{array}$ & $\begin{array}{l}\text { MIC level of antibiotics } \\
\text { in }(\mu \mathrm{g} / \mathrm{ml})\end{array}$ \\
\hline Gram-negative bacteria & E. coli 03 & 08 & 08 & 10 \\
& E.coliMTCC 9537 & 10 & 16 & 11 \\
& K.pneumonia 125 & 16 & 04 & 10 \\
& K.pneumonia MTCC 109 & 08 & 08 & 13 \\
& P.aeruginosa MTCC 741 & $\geq 68$ & $\geq 64$ & 13 \\
Gram-positive bacteria & S.flexneri MTCC 1457 & 10 & 09 & 09 \\
& S. aureus 20 & $\geq 16$ & 08 & 09 \\
& S.aureus MTCC 96 & 18 & 16 & 09 \\
\hline
\end{tabular}

Fig. 3 MIC levels of biogenic nanoparticles and antibiotics in different pathogenic bacteria

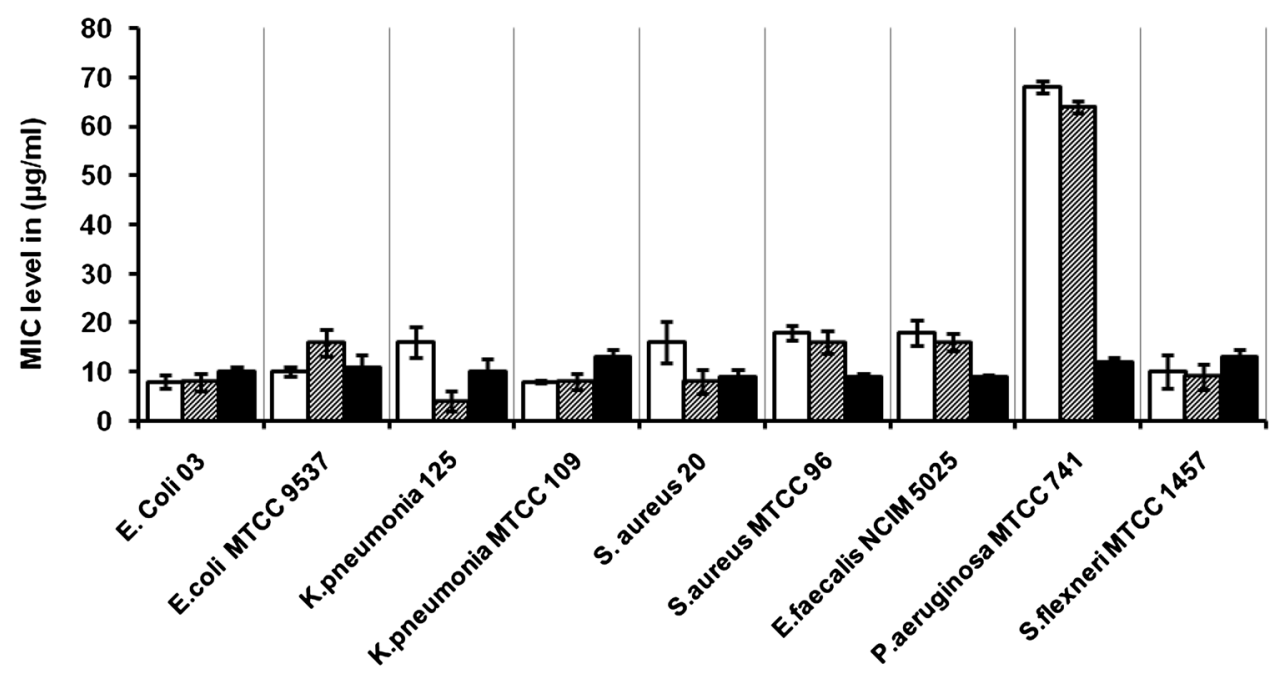

$\square$ MIC level of CuNPs in ( $\mu \mathrm{g} / \mathrm{ml})$ MIC level of ZnONPs in ( $\mu \mathrm{g} / \mathrm{ml})$ MIC level of Antibiotics in (mcg/ml) 
Fig. 4 Scanning electron microscopy of S.aureus 20 (MRSA) untreated control cells (a), cells treated with gentamicin antibiotic (b), cells treated with CuNPs $(\mathbf{c})$, cells treated with

CuNPs + Gentamicin (d), cells treated with Zinc ZnONPs (e), cells treated with

ZnONPs + Gentamicin (f)
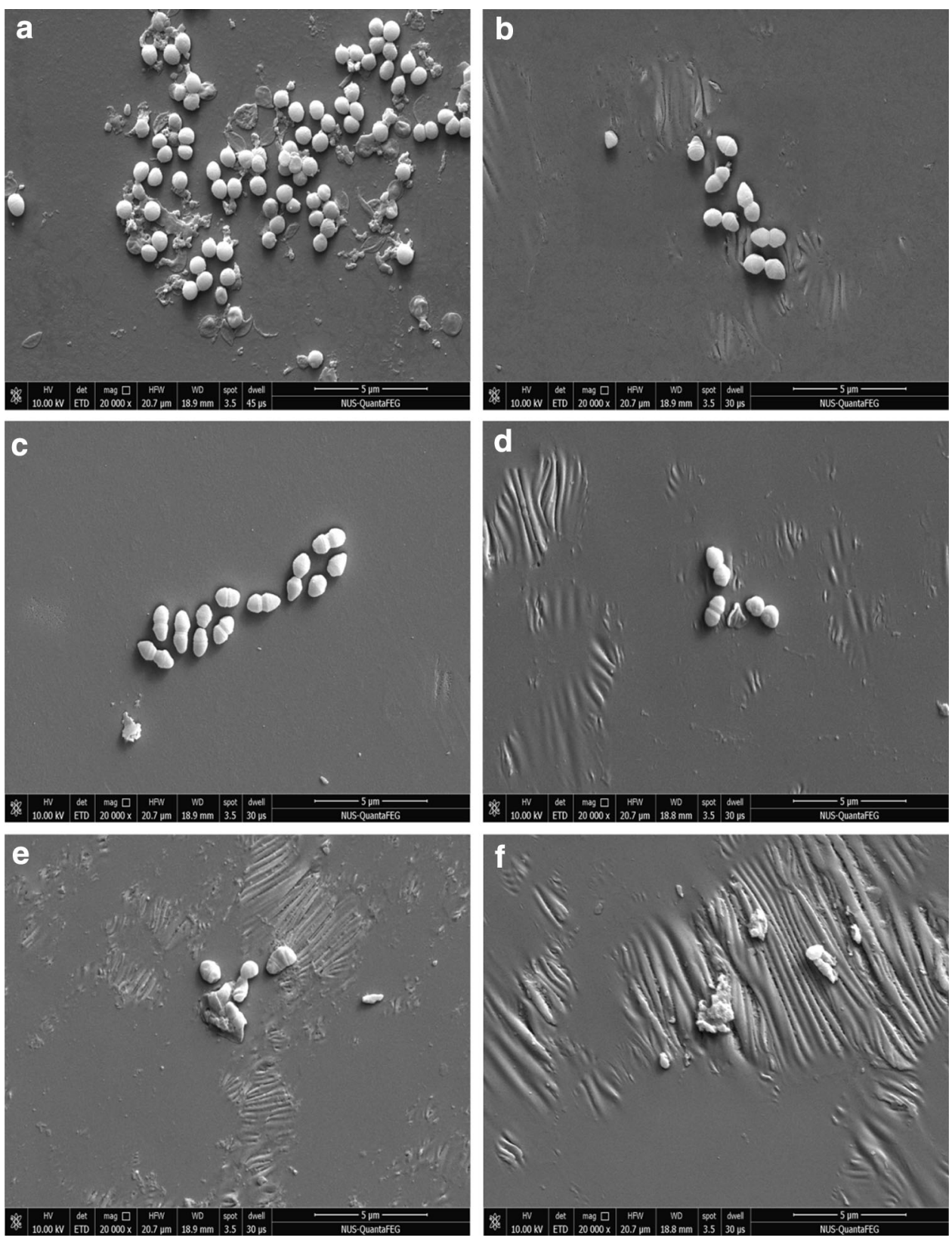

competence of CuNPs and ZnONPs in controlling pathogenic bacteria (Gram-positive and Gram-negative) by broth dilution method [29]. Each $6 \mathrm{~h}$ bacterial test strain was cultured in Luria-Bertani broth that was supplemented with $2,4,8,16$ up to $128 \mu \mathrm{g} / \mathrm{ml}$ of nanoparticles and antibiotics separately, and each culture was incubated at $37{ }^{\circ} \mathrm{C}$ for 18 and $24 \mathrm{~h}$. Absorbance was measured at $600 \mathrm{~nm}$ using BioPhotometer Plus (Eppendorf AG, Hamburg, Germany).

\section{Scanning electron microscopy}

The lethal effect of nanoparticles on the surface of bacteria was imaged by performing scanning electron microscopy of the
CuNPs, ZnONPs, and antibiotic to treated test strain. They were examined using an FEI QUANTA 650 FEG Scanning Electron Microscope (National University of Singapore, Singapore).

\section{Antibiofilm effect of CuNPs and ZnONPs} in combination with antibiotic against clinical MDR's and standard MTCC cultures

\section{Antibiofilm assay by test tube method}

A biofilm formation assay [30] and antibiofilm activity of the biogenic nanoparticles used in combination with standard antimicrobials were detected by the simple and modified test tube method and estimated by a 
Table 3 Percentage inhibition of CuNPs in combination with antibiotics in the test tube method

\begin{tabular}{|c|c|c|c|c|c|c|c|c|c|c|c|c|}
\hline \multirow[t]{2}{*}{ Pathogenic bacteria } & \multicolumn{3}{|c|}{ Copper nanoparticles } & \multicolumn{3}{|c|}{ Copper sulfate } & \multicolumn{3}{|c|}{ Antibiotic } & \multicolumn{3}{|c|}{$\begin{array}{l}\text { Copper } \\
\text { nanoparticles }+ \text { antibiotic }\end{array}$} \\
\hline & $\begin{array}{l}18 \mathrm{~h} \\
(\%)\end{array}$ & $\begin{array}{l}24 \mathrm{~h} \\
(\%)\end{array}$ & $\begin{array}{l}48 \mathrm{~h} \\
(\%)\end{array}$ & $\begin{array}{l}18 \mathrm{~h} \\
(\%)\end{array}$ & $\begin{array}{l}24 \mathrm{~h} \\
(\%)\end{array}$ & $\begin{array}{l}48 \mathrm{~h} \\
(\%)\end{array}$ & $\begin{array}{l}18 \mathrm{~h} \\
(\%)\end{array}$ & $\begin{array}{l}24 \mathrm{~h} \\
(\%)\end{array}$ & $\begin{array}{l}48 \mathrm{~h} \\
(\%)\end{array}$ & $\begin{array}{l}18 \mathrm{~h} \\
(\%)\end{array}$ & $\begin{array}{l}24 \mathrm{~h} \\
(\%)\end{array}$ & $\begin{array}{l}48 \mathrm{~h} \\
(\%)\end{array}$ \\
\hline E. coli 03 & 65 & 72.8 & 88.8 & 0.8 & 1.2 & 2.5 & 36.2 & 20.3 & 22.5 & 78 & 90 & 92 \\
\hline E.coli MTCC 9537 & 80.2 & 82 & 85.5 & 0.07 & 1.52 & 3.33 & - & - & - & 76.5 & 86 & 88 \\
\hline K.pneumonia 125 & 80.5 & 79.6 & 89.4 & 1.98 & 2.48 & 6.31 & 39.7 & 30.2 & 33.6 & 83.2 & 90.6 & 91.5 \\
\hline $\begin{array}{l}\text { K.pneumonia MTCC } \\
109\end{array}$ & 72.8 & 78 & 87.1 & - & - & - & 18.9 & 15.8 & 10 & 86.5 & 88.8 & 91.4 \\
\hline S. aureus 20 & 76.2 & 85 & 90.3 & - & - & - & 19.8 & 15.8 & 14.5 & 82.1 & 87.5 & 91.6 \\
\hline S. aureus MTCC 96 & 79.2 & 89 & 91.6 & - & - & 0.2 & 17.9 & 14.9 & 15.8 & 90.5 & 92.6 & 94.7 \\
\hline $\begin{array}{l}\text { E.faecalis NCIM5 } \\
025\end{array}$ & 84 & 82.6 & 85.5 & 17.2 & 14.6 & 16.3 & 29.7 & 24.8 & 0.5 & 90.6 & 90.8 & 95.9 \\
\hline $\begin{array}{l}\text { P.aeruginosa } \text { MTCC } \\
\quad 741\end{array}$ & 19.8 & - & 11.1 & - & - & - & - & - & - & - & 3.8 & 10.9 \\
\hline $\begin{array}{l}\text { S.flexneri MTCC } \\
1457\end{array}$ & 50.6 & 45.8 & 55.7 & 9.6 & 4.9 & 6.3 & 29.9 & 28.9 & 24.2 & 75.6 & 67.9 & 71.5 \\
\hline
\end{tabular}

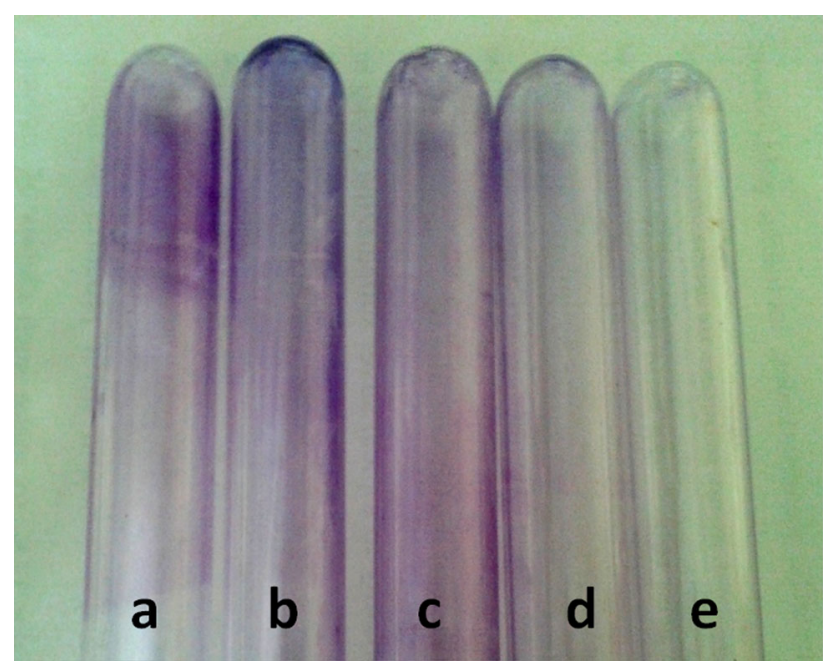

Fig. 5 Antibiofilm assay by the test tube method for S. aureus MTCC 96 at $48 \mathrm{~h}$. ( $a$ untreated, $b$ copper sulfate treated, $c$ antibiotic treated, $d$ CuNPs treated, $e$ CuNPs + Antibiotic)

spectrophotometer assay [31]. MDR and standard MTCC bacterial cultures were mixed with $2 \mathrm{ml}$ of tryptic soy broth (TSB), and for each culture, the following five separate plastic tubes were used; Tube 1: bacterial culture $+\mathrm{TSB}+\mathrm{Cu} / \mathrm{ZnO}$ nanoparticles from $50 \mathrm{mg} / \mathrm{ml}$ stock; Tube 2: bacterial culture + TSB + Antibiotics from $30 \mathrm{mg} / \mathrm{ml}$ stock; Tube 3: bacterial culture $+\mathrm{TSB}+35 \mu \mathrm{g} / \mathrm{ml}$ of copper sulfate/zinc sulfate solution from $100 \mathrm{mM}$ stock; Tube 4: bacterial culture $+\mathrm{TSB}+\mathrm{Cu} / \mathrm{ZnO}$ nanoparticles + antibiotics; and Tube 5: bacterial culture + TSB (control; as shown in

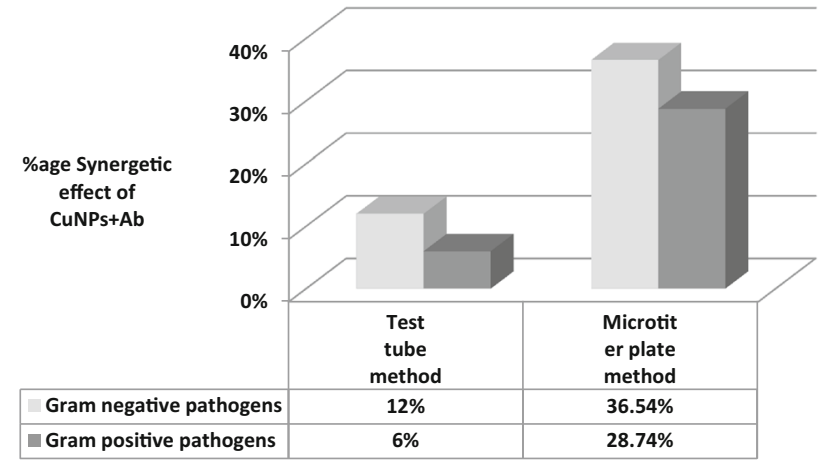

Fig. 6 Graphical representation of the percentage of synergetic effect of CuNPs $+\mathrm{Ab}$ shown in the test tube and microtiter plate method

Table 1). Experiments were designed separately for CuNPs and $\mathrm{ZnONPs.}$

\section{Antibiofilm assay by microtitre plate method}

Clinical isolates and MTCC cultures were grown overnight at $37{ }^{\circ} \mathrm{C}$ in TSB supplemented with $0.2 \%$ glucose [32]. The cultures were diluted 1:100 in medium, and $200 \mu \mathrm{l}$ of cell suspensions were used to inoculate separate wells of sterile flat-bottomed 96-well polystyrene microtiter plates (Corning Inc., Corning, NY, USA). For each organism, the five wells were maintained separately and repeated in triplicate. Additions of $0.3 \mu \mathrm{l}$ of copper/zinc oxide nanoparticles and antibiotics (concentrations as shown in Table 1) and copper sulfate/zinc sulfate solution from $100 \mathrm{mM}$ stock were incubated for $24 \mathrm{~h}$ at $37{ }^{\circ} \mathrm{C}$ without 


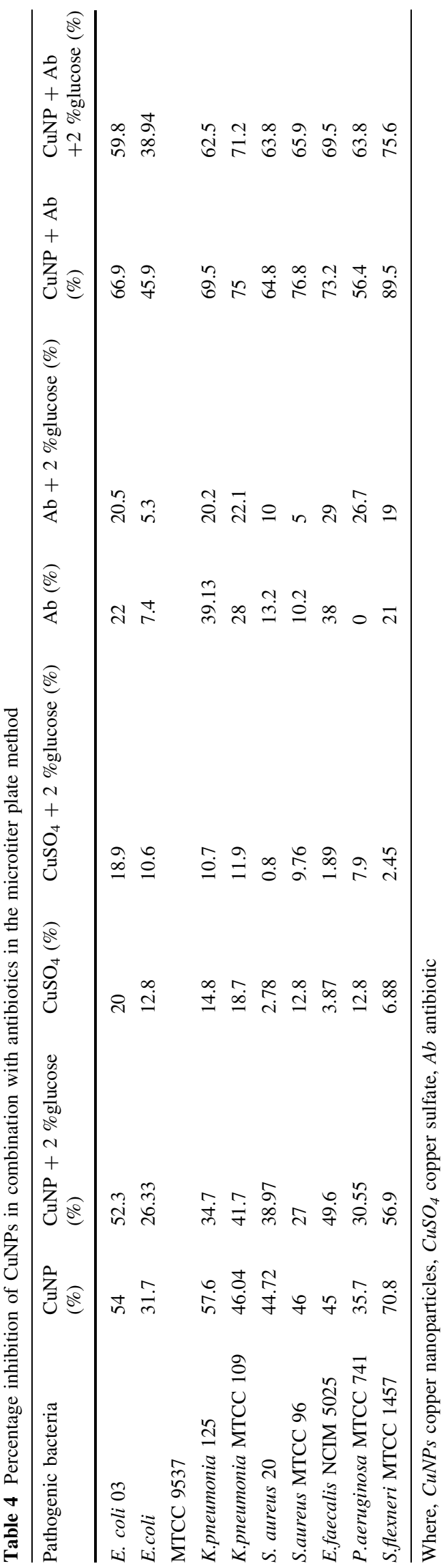

shaking. One hundred microliters of destaining solution was measured at $490 \mathrm{~nm}$ using a microtiter plate reader (iMark Microplate Reader S/N 12883 Biorad Pvt Ltd. India). Media without inoculums were used as control. The percentage of biofilm inhibition (1) and the percentage of synergetic effect (2) were calculated using the following equations [31]:

\%age of biofilm inhibition

$$
=\frac{(O D 490 \text { in control }-O D 490 \text { in treatment })}{O D 490 \text { in control }} \times 100
$$

\%age of synergetic effect

$=\frac{[\% \text { biofilm inhibition for }(\mathrm{NPs}+\mathrm{Ab})-\% \text { biofilm inhibition for NPs }]}{\% \text { biofilm inhibition for }(\mathrm{NPs}+\mathrm{Ab})} \times 100$

(where: NPs; biogenic CuNPs and ZnONPs, Ab; antibiotic).

\section{Results and discussion}

In the present investigation, the Gram-positive nonpathogenic bacterium Enterococcus faecalis was found notable in producing CuNPs and ZnONPs of different sizes ranging from 1 to $100 \mathrm{~nm}$ in distribution. TEM analysis reports the presence of biosynthesized CuNPs and ZnONPs from E. faecalis with core shell morphology of size 12-90 nm and spherical in shape for CuNPs and ZnONPs ranging from 16 to $96 \mathrm{~nm}$ with marginal variation and aggregate form (shown in Fig. 1).

Crystalline nature of the biogenic CuNPs and ZnONPs was confirmed by X-ray diffraction analysis. The XRD pattern clearly shows that the extracellular synthesis of CuNPs and ZnONPs formed by the reduction of sulfate ions from $100 \mathrm{mM}$ copper sulfate and zinc sulfate using culture supernatant of E. faecalis. CuNPs exhibited four prominent Bragg reflections around $38.19^{\circ}, 44.22^{\circ}, 64.65^{\circ}$, and $77.7^{\circ}$ (Fig. 2a). The fraction between the intensity of the (111) plane higher than the (200), (220), and (311) diffraction peaks. Intensity of the (111) facets for the very sharp diffraction peak at $38.19^{\circ}$ is considered for the face centered cubic structure [33]. The (111) facet is extremely reactive and stable due to high rate of electron transfer. The XRD facets of the CuNPs compared and indexed with standard copper which was published by JCPDS file (JCPDS card No: 41-0254). The mean size of CuNPs was calculated using the Debye-Scherer equation by determining the width of the (111) and the similar Bragg reflection was found to be around $32.54 \mathrm{~nm}$. The absence of diffraction peak in ZnONPs sample (shown in Fig. 2b) confirms the amorphous character of the sample. 
Table 5 Percentage of synergetic effect of CuNPs shown in the test tube and microtiter plate method

\begin{tabular}{|c|c|c|c|c|c|c|}
\hline \multirow[t]{2}{*}{ Pathogenic bacteria } & \multirow[t]{2}{*}{ Antibiotics } & \multicolumn{3}{|c|}{$\begin{array}{l}\text { \% Age of synergetic effect } \\
\text { in Test tube method }\end{array}$} & \multicolumn{2}{|c|}{$\begin{array}{l}\% \text { Age of synergetic effect in Microtitre } \\
\text { plate method for } 72 \mathrm{~h}\end{array}$} \\
\hline & & $18 \mathrm{~h}(\%)$ & $24 \mathrm{~h}(\%)$ & $48 \mathrm{~h}(\%)$ & $\mathrm{CuNP}+\mathrm{Ab}(\%)$ & $\mathrm{CuNP}+\mathrm{Ab}+2 \%$ glucose $(\%)$ \\
\hline E. coli 03 & Ceftriaxone & 16.6 & 19.1 & 3.4 & 19.2 & 12.5 \\
\hline E.coli MTCC 9537 & Ceftriaxone & - & 4.6 & 2.8 & 30.9 & 32.3 \\
\hline K.pneumonia 125 & Ceftazidime & 3.24 & 12.14 & 2.2 & 17.12 & 44.4 \\
\hline K.pneumonia МТСC 109 & Ceftazidime & 15.8 & 12.16 & 4.7 & 38.6 & 41.4 \\
\hline S. aureus 20 & Gentamicin & 7 & 2.8 & 1.4 & 30.9 & 38.9 \\
\hline S.aureus MTCC 96 & Gentamicin & 12.4 & 3.8 & 3.2 & 40.10 & 24.7 \\
\hline E.faecalis NCIM 5025 & Gentamicin & 7.2 & 9 & 10.8 & 38.5 & 28.6 \\
\hline P.aeruginosa MTCC 741 & Ceftazidime & - & - & - & 36.7 & 52.11 \\
\hline S.flexneri MTCC 1457 & Ceftazidime & 33 & 32.5 & 22 & 20.8 & 24.7 \\
\hline
\end{tabular}

Table 6 Percentage inhibition of ZnONPs in combination with antibiotics in the test tube method

\begin{tabular}{|c|c|c|c|c|c|c|c|c|c|c|c|c|}
\hline \multirow[t]{2}{*}{ Pathogenic bacteria } & \multicolumn{3}{|c|}{ ZnONPs } & \multicolumn{3}{|c|}{ Zinc sulfate } & \multicolumn{3}{|c|}{ Antibiotic } & \multicolumn{3}{|c|}{ ZnONPs + antibiotic } \\
\hline & $\begin{array}{l}18 \mathrm{~h} \\
(\%)\end{array}$ & $\begin{array}{l}24 \mathrm{~h} \\
(\%)\end{array}$ & $\begin{array}{l}48 \mathrm{~h} \\
(\%)\end{array}$ & $\begin{array}{l}18 \mathrm{~h} \\
(\%)\end{array}$ & $\begin{array}{l}24 \mathrm{~h} \\
(\%)\end{array}$ & $\begin{array}{l}48 \mathrm{~h} \\
(\%)\end{array}$ & $\begin{array}{l}18 \mathrm{~h} \\
(\%)\end{array}$ & $\begin{array}{l}24 \mathrm{~h} \\
(\%)\end{array}$ & $\begin{array}{l}48 \mathrm{~h} \\
(\%)\end{array}$ & $\begin{array}{l}18 \mathrm{~h} \\
(\%)\end{array}$ & $\begin{array}{l}24 \mathrm{~h} \\
(\%)\end{array}$ & $\begin{array}{l}48 \mathrm{~h} \\
(\%)\end{array}$ \\
\hline E. coli 03 & 80.3 & 85.4 & 89.7 & 4.89 & 3.6 & 7.5 & 36.2 & 20.3 & 22.5 & 82.7 & 88.8 & 89.7 \\
\hline $\begin{array}{l}\text { E.coli } \\
\text { MTCC } 9537\end{array}$ & 80.7 & 86.8 & 88 & - & - & - & - & - & - & 92.8 & 89.9 & 91.1 \\
\hline K.pneumonia 125 & 93.8 & 89 & 93.6 & 9.6 & 9.8 & 9.4 & 39.7 & 30.2 & 33.6 & 99.1 & 98.5 & 95.7 \\
\hline $\begin{array}{l}\text { K.pneumonia MTCC } \\
109\end{array}$ & 96.8 & 92.7 & 91.4 & - & - & - & 18.9 & 15.8 & 10 & 98.5 & 96.4 & 94.2 \\
\hline S. aureus 20 & 97.5 & 96.4 & 94.8 & 10 & - & - & 19.8 & 15.8 & 14.5 & 98.7 & 95.4 & 97.9 \\
\hline S.aureus MTCC 96 & 95.9 & 94.8 & 93.7 & 14.8 & 15.2 & 15.8 & 17.9 & 14.9 & 15.8 & 97.9 & 97.5 & 95.8 \\
\hline $\begin{array}{l}\text { E.faecalis NCIM } \\
\quad 5025\end{array}$ & 94.7 & 89.6 & 90.8 & 9.6 & 9.6 & 9.1 & 29.7 & 24.8 & 0.5 & 96.8 & 94.8 & 93.8 \\
\hline $\begin{array}{l}\text { P.aeruginosa } \text { MTCC } \\
741\end{array}$ & 10.7 & - & 9 & - & - & - & - & - & - & 7.8 & 3.8 & 3.0 \\
\hline $\begin{array}{l}\text { S.flexneri MTCC } \\
1457\end{array}$ & 97.5 & 96.7 & 93.6 & 3.8 & 2.8 & 2.3 & 29.9 & 28.9 & 24.2 & 96.9 & 95.8 & 93.7 \\
\hline
\end{tabular}

Where, $\mathrm{ZnONPs}$ zinc oxide nanoparticles, $\mathrm{ZnSO}_{4}$ zinc sulfate

The antimicrobial activities of the biogenic CuNPs and ZnONPs against Gram-negative and Gram-positive bacteria were estimated through MIC by the broth dilution method. The tested concentrations for biogenic CuNPs and ZnONPs were from 2 to $128 \mu \mathrm{g} / \mathrm{ml}$, as shown in Table 2 and Fig. 3. The results demonstrated that effective doses of biogenic CuNPs, ZnONPs, and antibiotics for both Gram-positive and Gram-negative bacteria are different. Biogenic nanoparticles are efficient inhibitors against both Gram-positive and Gram-negative bacteria in contrast to antibiotics. MIC values of CuNPs and ZnONPs against Gram-negative bacteria include E. coli $03, E$. coli MTCC 9537, K. pneumonia $125, K$. pneumonia MTCC 109 , and $S$. flexneri MTCC 1457 ranging from 8 to $16 \mu \mathrm{g} / \mathrm{ml}$. In addition, 18 to $\geq 68 \mu \mathrm{g} / \mathrm{ml}$ of CuNPs and ZnONPs showed inhibition kinetics against Gram-positive pathogens, including methicillin-resistant $S$. aureus $20, S$. aureus MTCC 96, E. faecalis NCIM 5025, and the Gram-negative bacteria $P$. Aeruginosa MTCC 741. This disparity could be due to differences in the membrane structure and the composition of the cell wall, thereby affecting access of the CuNPs and ZnONPs. Cell walls of both Gram-positive and Gram-negative bacteria have negative charge because of the presence of teichoic acids and lipopolysaccharides, respectively [30]. Many researchers found that the antibacterial effect of nanoparticles was more prominent against Gram-negative bacteria than Gram-positive bacteria. This could be due to the excess of negative charges 


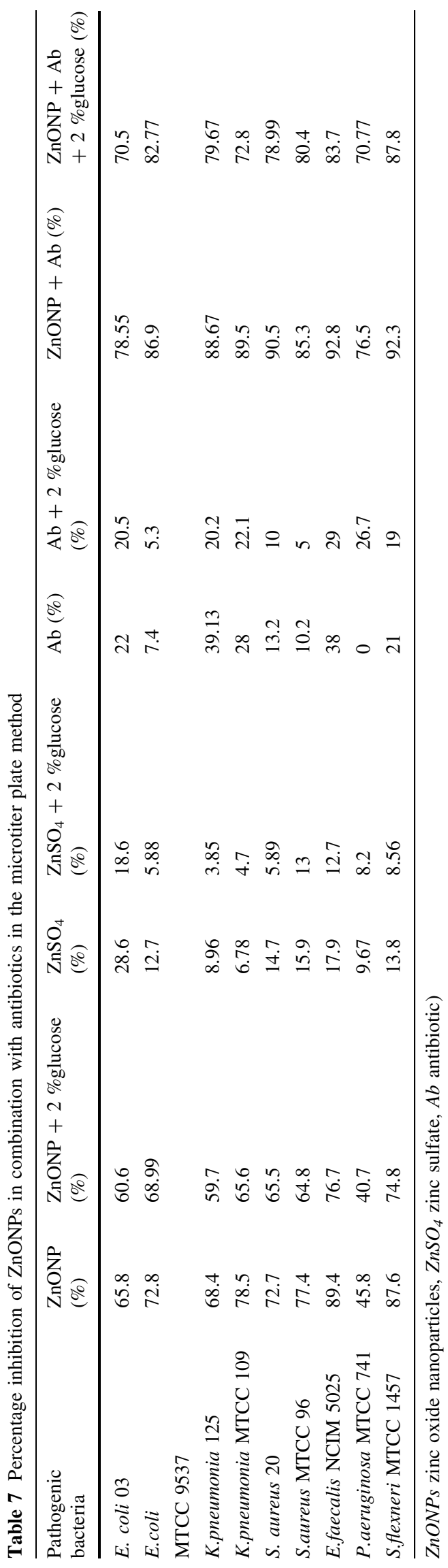

on the Gram-negative bacteria which assists the burly interaction between nanoparticles and cell wall components of the bacteria [34]. Absolutely, the exact mechanism of inhibition by the nanoparticles on the microorganisms depends on their small size and high surface area to volume ratio $(\mathrm{S} / \mathrm{V})$, which permit them to interact closely with the membranes of the microbe [34]. Furthermore, the biosynthesized CuNPs and ZnONPs in this study displayed the promising antibacterial activity against Gram-negative subsequent to Gram-positive bacteria, which could be attributed to their size less than $100 \mathrm{~nm}$ and greatest surface area to volume ratio; therefore, the contact with bacteria is the greatest. This could be the reason why they exhibit the best antibacterial activity.

These results also specify that there were no significant antibacterial activities observed at concentrations less than $8 \mu \mathrm{g} / \mathrm{ml}$ by any biogenic nanoparticles. In contrast, MIC levels of antibiotics were more similar to the nanoparticles against several Gram-negative bacteria. The dissimilarity in the MIC results against both Gram-positive and Gramnegative bacteria might be due to differences in cell wall structure. Thus, it was concluded that CuNPs and ZnONPs inhibited the growth of all the tested microorganisms.

\section{Morphological analysis by scanning electron microscopy}

Scanning electron microscopy was used to determine the morphological changes of the $S$. aureus 20 , after treatment with antibiotic, nanoparticles (NPs) alone, and antibiotics with nanoparticle (Antibiotic + NPs). Cells without any treatment (control) showed normal morphology, with a multilayered surface consisting of the outer membrane (Fig. 4a). In contrast, the cells exposed to $>9 \mu \mathrm{g} / \mathrm{ml}$ concentration of gentamicin and $>16 \mu \mathrm{g} / \mathrm{ml}$ of CuNPs for $24 \mathrm{~h}$ showed increased cell size and change in cell shape (Fig. 4b). The cells treated with in combination of CuNPs + Antibiotic (Fig. 4c, d) showed deformed morphology lacking a cytoplasmic membrane. For the cells treated with $\mathrm{ZnONPs}+$ Antibiotic $(>8+>9 \mu \mathrm{g} / \mathrm{ml})$, the outer membrane was progressively lost, and the cytoplasm tended to spill out of the cell leading to cell death, which corresponded to the final stage of cell disruption, plasmolysis, and partial disappearance of the cytoplasmic membrane (in Fig. 4e, f). Finally, SEM studies proved that CuNPs and ZnONPs used in combination with gentamicin had the highest antibacterial activity when compared with CuNPs, ZnONPs, and antibiotics alone treatment.

\section{Antibiofilm assay}

Various applications of nanoparticle-based therapies have gained attraction across several biomedical fields. Due to 
Table 8 Percentage of synergetic effect of ZnONPs showed in the test tube and microtiter plate method

\begin{tabular}{|c|c|c|c|c|c|c|}
\hline \multirow[t]{2}{*}{ Pathogenic bacteria } & \multirow[t]{2}{*}{ Antibiotics } & \multicolumn{3}{|c|}{$\begin{array}{l}\text { \%Age of synergetic effect in Test tube } \\
\text { method }\end{array}$} & \multicolumn{2}{|c|}{$\begin{array}{l}\% \text { Age of synergetic effect in Microtiter plate method for } \\
72 \mathrm{~h}\end{array}$} \\
\hline & & $18 \mathrm{~h}(\%)$ & $24 \mathrm{~h}(\%)$ & $48 \mathrm{~h}(\%)$ & $\mathrm{ZnONP}+\mathrm{Ab}(\%)$ & $\mathrm{ZnONP}+\mathrm{Ab}+2 \%$ glucose $(\%)$ \\
\hline E. coli 03 & Ceftriaxone & 2.9 & 3.7 & 0 & 16.23 & 14 \\
\hline E.coli MTCC 9537 & Ceftriaxone & 13 & 3.4 & 3.4 & 16.22 & 15.7 \\
\hline K.pneumonia 125 & Ceftazidime & 5.3 & 9.6 & 2.1 & 22.8 & 0.06 \\
\hline K.pneumonia МТСC 109 & Ceftazidime & 1.72 & 3.8 & 2.9 & 12.2 & 9.8 \\
\hline S. aureus 20 & Gentamicin & 1.2 & - & 3.1 & 19.6 & 17 \\
\hline S.aureus MTCC 96 & Gentamicin & 2 & 2.7 & 2.17 & 9.2 & 19.4 \\
\hline E.faecalis NCIM 5025 & Gentamicin & 2.1 & 5.4 & 3.1 & 3.6 & 8.3 \\
\hline P.aeruginosa MTCC 741 & Ceftazidime & - & - & - & 40.13 & 42.48 \\
\hline S.flexneri МТCC 1457 & Ceftazidime & - & - & - & 5.09 & 14.8 \\
\hline
\end{tabular}

the resistant nature of biofilms, eradication of biofilm-related diseases/infection is challenging [35]. Efforts are being made to use penetrating capacity of nanoparticles in biofilm studies [36-38]. Further application of nanotechnology could be a way to combat biofilm infections.

This study investigated inhibition of biofilm activity by biosynthesized nanoparticles. Activity of Gram-positive and Gram-negative bacteria was ceased under in vitro conditions, subsequently leading to the inhibition of biofilm formation. Both CuNPs and ZnONPs have been used to inhibit the initial stage of biofilm formation.

The results for both test tube and microtiter plate wells showed that for all the bacterial strains tested (except for P.aeruginosa MTCC 741), biologically synthesized CuNPs and ZnONPs inhibited the activity of biofilm formation at its irreversible adhesion stage (also known as Initial stage). Interestingly, an inhibition of initial stage biofilm activity was observed at the MIC values of CuNPs and ZnONPs.

Furthermore, this study also revealed the synergistic effect of CuNPs and ZnONPs of antibiofilm activity against different pathogenic bacteria in the presence of antibiotics. Biofilm production has been reported in all strains. The results from the test tube method indicated that CuNPs alone reduce the biofilm activity by approximately $\geq 9 \%$ in Gram-negative and $\geq 2 \%$ in Gram-positive bacteria. Combination of CuNPs and antibiotics showed more effective biofilm inhibition activity in Gram-negative and Gram-positive bacteria by $12 \%$ and $6 \%$, respectively (shown in Tables 3 and 5, Figs. 5 and 6). Samples treated with antibiotics and positive control alone showed negligible activity on biofilm prevention/inhibition. In the microtiter method, $36.54 \%$ and $28.74 \%$ of antibiofilm activity was recorded for Gram-negative and Gram-positive bacteria, respectively (Tables 4, 5; Fig. 6).

Antibiofilm activity of ZnONPs in combination with antibiotic showed comparatively less activity against

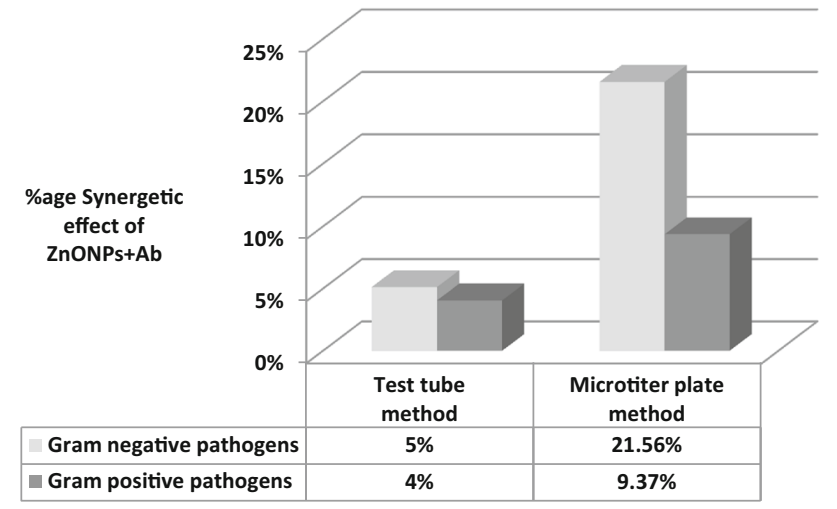

Fig. 7 Graphical representation of the percentage of synergetic effect of $\mathrm{ZnONPs}+\mathrm{Ab}$ shown in the test tube and microtiter plate method

Gram-negative and Gram-positive bacteria in both the test tube and the microtiter plate method compared to CuNPs. In the test tube method, ZnONPs showed 5 and $4 \%$ of antibiofilm activity against Gram-negative and Gram-positive bacteria, respectively (shown in Table 6). Enhanced antibiofilm activity was reported from the microtiter plate method (21.56 \% for Gram-negative and $9.37 \%$ for Grampositive bacteria, as shown in Table 7). Using the microtiter plate assay method, we found that the synergetic effects of CuNPs and ZnONPs (Table 8; Fig. 7) with specific antibiotic in the presence of $2 \%$ glucose are relatively high compared with the treatment without glucose. Due to bonding interactions, increased synergistic effects among antibiotics and nanoparticles were observed. In addition, the large surface area and presence of functional groups, such as hydroxyl, amino, etc., lead nanoparticles to interact with antibiotics by chelating reactions [39]. However, the mechanistic action of NPs with antibiotics in biofilm-related studies has yet to be demonstrated. For the NP therapies, the results indicates, microtiter plate assay method is an accurate and reproducible method for 
antibiofilm screening, and assay serves as a reliable quantitative tool for determining the antibiofilm potential of nanoparticles in combination with antibiotic agents against several clinical isolates. Collectively, these findings conclude that the enhanced synergistic effect of biosynthesized nanoparticles in combination with antibiotics against pathogenic bacteria could be used as potent adjuvant therapy against several bacterial infections.

The difference in the inhibitory activity may also be explained by several factors, including efficacy in antimicrobial activity, biosorption-dependent manner, physical properties, such as the size of the nanoparticle, penetration abilities, and other chemical properties effecting the affinity between the materials and the biofilms [40]. The results suggest that CuNPs were better antibiofilm agents against the Gram-negative and Gram-positive bacteria than ZnONPs.

\section{Conclusion}

This study was designed to elucidate the enhanced antibiofilm effects of the third generation antibiotics with biogenic CuNPs and ZnONPs (as shown in Fig. 8). The need for higher dosage of NPs and antibiotics could be reduced by the synergistic action of antimicrobial agents, and this phenomenon also minimizes side effects. This study demonstrated improvement of the bactericidal property of nanoparticles by understanding their synergistic effect with other antimicrobial agents to improve their efficacy against various pathogenic microbes. The increased antibiofilm activity of CuNPs was more promising than that of ZnONPs for targeting Gram-negative and Gram-positive bacteria. The increased inhibition activity of CuNPs on bacteria is associated with release of free ions from nanoparticles. In addition, the potentiality is, furthermore, enhanced by its small size $(12-90 \mathrm{~nm})$ and high surface area to volume ratio which permits them to interact intimately with microbial membranes. Antimicrobial activity is due to its affinity to instability between its oxidation states. Differentiating copper ions from other trace metals results in the production of hydroxyl radicals that subsequently bind with DNA molecules and lead to disorder of the helical structure by crosslinking within and between the nucleic acid strands and damage essential proteins by binding to the sulfhydryl amino and carboxyl groups of amino acids and denatures the protein. The exact mechanism behind is still not known and needs to be further investigated. Based on all of these studies, antimicrobial characteristics of CuNPs is by denaturing affect of $\mathrm{Cu}$ ion on proteins and enzymes in microbes [41]. In addition, NPs could be used as an adjuvant therapy for the treatment of various infectious diseases caused by Gramnegative and Gram-positive bacteria. Thus, our findings support the notion that NPs have effective antibiofilm activity that could be used to enhance the action of existing antibiotics against Gram-negative and Gram-positive bacteria.
Fig. 8 Graphical abstract on "synergistic antibacterial and antibiofilm activity of biogenic CuNPs and ZnONPsantimicrobials against pathogenic bacteria"

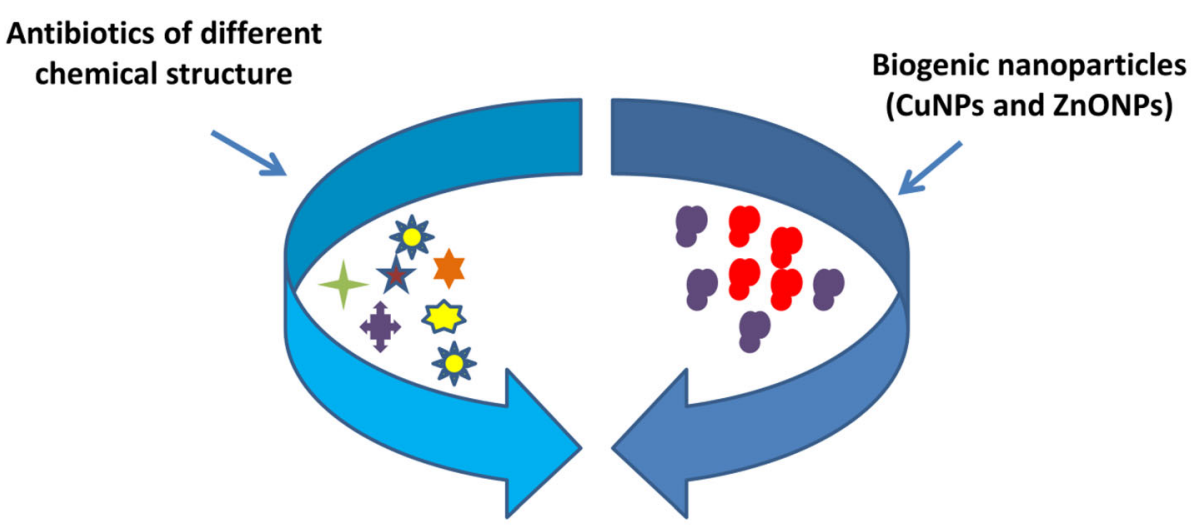

Non-specific and strong

Bactericidal action/Biofilm

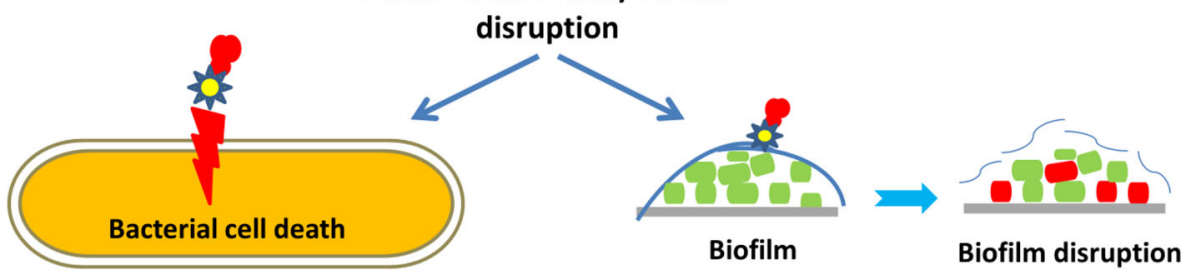

Live bacteria Dead bacteria EPS 
Author's contribution $\mathrm{KCR}$ and $\mathrm{AC}$ conceived and preformed the experiments. HHK and NKD assisted with experiments. NKD contributed in SEM imaging and analysis of results. All authors contributed in interpreting results, arranging tables, illustrations and preparing the manuscript. KCR improved experimental design and manuscript. All authors read and approved the final manuscript.

Acknowledgments This work was funded by University Grants Commission (Grant Number: MRP-MAJOR-BIOT-2013-15248), New Delhi, India and the authors gratefully acknowledge the Department of Biotechnology, Gulbarga University, Gulbarga for providing the facilities to pursue this research.

\section{Compliance with ethical standards}

Disclosure statement No competing financial interests exist.

Open Access This article is distributed under the terms of the Creative Commons Attribution 4.0 International License (http://crea tivecommons.org/licenses/by/4.0/), which permits unrestricted use, distribution, and reproduction in any medium, provided you give appropriate credit to the original author(s) and the source, provide a link to the Creative Commons license, and indicate if changes were made.

\section{References}

1. Høiby, N., Bjarnsholt, T., Givskov, M., Molin, S., Ciofu, O.: Antibiotic resistance of bacterial biofilms. Int. J. Antimicrob. Agents 35(4), 322-332 (2010)

2. Hall-Stoodley, L., Costerton, J.W., Stoodley, P.: Bacterial biofilms: from the Natural environment to infectious diseases. Nat. Rev. Micro 2(2), 95-108 (2004)

3. Markowska, K., Grudniak, A.M., Wolska, K.I.: Silver nanoparticles as an alternative strategy against bacterial biofilms. Acta Biochim. Pol. 60(4), 523-530 (2013)

4. Ventola, C.L.: The antibiotic resistance crisis: part 1: causes and threats. P t 40(4), 277-283 (2015)

5. Chen, M., Yu, Q., Sun, H.: Novel strategies for the prevention and treatment of biofilm related infections. Int. J. Mol. Sci. 14(9), 18488-18501 (2013)

6. Parsek, M.R., Singh, P.K.: Bacterial biofilms: an emerging link to disease pathogenesis. Ann. Rev. Microbiol. 57, 677-701 (2003)

7. Donlan, R.M., Costerton, J.W.: Biofilms: survival mechanisms of clinically relevant microorganisms. Clin. Microbiol. Rev. 15(2), 167-193 (2002)

8. Yokoi, N., Okada, K., Sugita, J., Kinoshita, S.: Acute conjunctivitis associated with biofilm formation on a punctal plug. Jpn. J. Ophthalmol. 44(5), 559-560 (2000)

9. LewisOscar, F., MubarakAli, Davoodbasha, Nithya, C., Priyanka, R., Gopinath, V., Alharbi, N.S., Thajuddin, N.: One pot synthesis and antibiofilm potential of copper nanoparticles (CuNPs) against clinical strains of Pseudomonas aeruginosa. Biofouling 31(4), 379-391 (2015)

10. Sondi, I., Salopek-Sondi, B.: Silver nanoparticles as antimicrobial agent: a case study on E. coli as a model for Gramnegative bacteria. J. Colloid Interface Sci. 275, 177-182 (2004)

11. Kathiresan, K., Manivannan, S., Nabeel, M.A., Dhivya, B.: Studies on silver nanoparticles synthesized by a marine fungus, Penicillium fellutanum isolated from coastal mangrove sediment. Colloids Surf. B 71, 133-137 (2009)
12. Allahverdiyev, A.M., Kon, K.V., Abamor, E.S., Bagirova, M., Rafailovich, M.: Coping with antibiotic resistance: combining nanoparticles with antibiotics and other antimicrobial agents. Expert Rev. Anti Infect. Ther. 9(11), 1035-1052 (2011)

13. Cho, K.H., Park, J.E., Osaka, T., Park, S.G.: The study of antimicrobial activity and preservative effects of nanosilver ingredient. Electrochim. Acta 51, 956-960 (2005)

14. Wilks, S.A., Michels, H., Keevil, C.W.: The survival of Escherichia coli $\mathrm{O} 157$ on a range of metal surfaces. Int. J. Food Microbiol. 105, 445-454 (2005)

15. Casey, A.L., Adams, D., Karpanen, T.J., Lambert, P.A., Cookson, B.D., Nightingale, P.: Role of copper in reducing hospital environment contamination. J. Hosp. Infect. 74, 72-77 (2010)

16. Borkow, G., Gabbay, J., Dardik, R., Eidelman, A.I., Lavie, Y., Grunfeld, Y., Ikher, S., Huszar, M., Zatcoff, C., Marikovsky, M.: Molecular mechanisms of enhanced wound healing by copper oxide-impregnated dressings. Wound Repair Regen. 18, 266-275 (2010)

17. Eshed, M., Lellouche, J., Gedanken, A., Banin, E.: A Zn-doped $\mathrm{CuO}$ nanocomposite shows enhanced antibiofilm and antibacterial activities against Streptococcus mutans compared to nanosized CuO. Adv Funct. Mat. 24, 1382-1390 (2014)

18. Christena, L.R., Mangalagowri, V., Pradheeba, P., Ahmed, K.B.A., Shalini, B.I.S., Vidyalakshmi, M.: Copper nanoparticles as an efflux pump inhibitor to tackle drug resistant bacteria. RSC Adv. 5, 12899-12909 (2015)

19. Begum, A.N., Mondal, S., Basu, S., Laskar, A.R., Mandal, D.: Colloids Surf. B 71, 113-118 (2009)

20. Applerot, G., Lellouche, J., Perkas, N., Nitzan, Y., Gedanken, A., Banin, E.: $\mathrm{ZnO}$ nanoparticle-coated surfaces inhibit bacterial biofilm formation and increase antibiotic susceptibility. RSC Advances. 2, 2314-2321 (2012)

21. Brayner, R., Ferrari-Iliou, R., Brivois, N., Djediat, S., Benedetti, M.F., Fievet, F.: Toxicological impact studies based on Escherichia coli bacteria in ultrafine $\mathrm{ZnO}$ nanoparticles colloidal medium. Nano Lett. 6, 866-870 (2006)

22. Thill, A., Zeyons, O., Spalla, O., Chauvat, F., Rose, J., Auffan, M., Flank, A.M.: Cytotoxicity of $\mathrm{CeO}_{2}$ nanoparticles for Escherichia coli physico-chemical insight of the cytotoxicitymechanism. Environ. Sci. Technol. 40, 6151-6156 (2006)

23. Reddy, K.M., Feris, K., Bell, J., Wingett, D.G., Hanley, C., Punnoose, A.: Selective toxicity of zinc oxide nanoparticles to prokaryotic and eukaryotic systems. Appl. Phys. Lett. 90, 2139021-2139023 (2007)

24. Zhang, L.L., Jiang, Y.H., Ding, Y.L., Povey, M., York, D.: Investigation into the antibacterial behaviour of suspensions of $\mathrm{ZnO}$ nanoparticles (zno nanofluids). J. Nanopart. Res. 9, 479-489 (2007)

25. Thati, V., Roy, A.S., Ambika Prasad, M.V.N., Shivannavar, C.T., Gaddad, S.M.: Nanostructured Zinc oxide enhances the activity of antibiotics against Staphylococcus aureus. J. Biosci. Tech. 1, $64(2010)$

26. Luo, Z., Wu, Q., Xue, J., Ding, Y.: Selectively enhanced antibacterial effects and ultraviolet activation of antibiotics with $\mathrm{ZnO}$ nanorods against Escherichia coli. J. Biomed. Nanotechnol. 9, 69 (2013)

27. Ashajyothi, C., Jahanara, K., Chandrakanth, K.R.: Biosynthesis and characterization of copper nanoparticles from Enterococcus faecalis. Int. J. Pharma Biosci. 5(4), 204-211 (2014)

28. Ashajyothi, C., Manjunath, R., Narasanna, K., Chandrakanth, R.: Antibacterial activity of Biogenic Zinc oxide nanopaticals synthesized from Enterococcus faecalis. Int. J. Chemtech Res. 69(5), 3131-3136 (2014)

29. Clinical and Laboratory Standards Institute, Performance standards for antimicrobial susceptibility testing. Performance standards for antimicrobial susceptibility testing. Twenty-Second 
informational supplement. Document M100- S22, CLSI. 2012, Wayne, PA

30. Mathur, T., Khan, S.S., Upadhyay, D.J., Fatma, T., Rattan, A.: Detection of biofilm formation among the clinical isolates of staphylococci: an evaluation of three different screening methods. Indian J. Med. Microbiol. 24(25), 9 (2006)

31. Ashajyothi C, Manjunath, K., Chandrakanth, R.: Prevention of multiple drug resistant bacterial biofilm by synergistic action of biogenic silver nanoparticle and antimicrobials. J. Microbiol. Biotech. Res. 5(1), 7 (2015)

32. Mohamed, J.A., Huang, W., Nallapareddy, S.R., Teng, F., Murray, B.E.: Influence of origin of isolates, especially endocarditis isolates, and various genes on biofilm formation by Enterococcus faecalis. Infect. Immun. 72(6), 3658-3663 (2004)

33. Ramyadevi, J., Jeyasubramanian, K., Marikani, A., Rajakumar, G., AbdulRahuman, A.: Synthesis and antimicrobial activity of copper nanoparticles. Mater. Lett. 71, 114-116 (2012)

34. Eman, A., Rasha A., Ahmed: Synthesis of copper nanoparticles with various sizes and shapes: application as a superior nonenzymatic sensor and antibacterial agent. Int. J. Electrochem. Sci. 11, 4712-4723 (2016)

35. Lewis, K.: Riddle of biofilm resistance. Antimicrob. Agents Chemother. 45, 8 (2001)
36. Li, Xiaoning, Yeh, Y.C., Giri, K., Mount, R., Landis, R.F., Prakash, Y.S., Rotello, V.M.: Control of nanoparticle penetration into biofilms through surface design. Chem. Commun. 51(2), 282-285 (2015)

37. Ikuma, K., Decho, A.W., Lau, B.L.T.: When nanoparticles meet biofilms-interactions guiding the environmental fate and accumulation of nanoparticles. Frontiers in Microbiology 6, 591 (2015)

38. Wang, L.-S., Gupta, A., Rotello, V.M.: Nanomaterials for the Treatment of Bacterial Biofilms. ACS Infect. Dis. 2(1), 3-4 (2016)

39. Dhas, S.P., Mukherjee, A., Chandrasekaran, N.: Synergistic effect of biogenic silver nanocolloid in combination with antibiotics: a potent therapeutic agent. Int. J. Pharm. Pharm. Sci. 5(1), 292-295 (2013)

40. Park, H.J., Kim, H.Y., Cha, S, Ahn C.H., Roh, J, Park, S, Kim S, Choi K, Yi J, Kim Y, Yoon J.: Removal characteristics of engineered nanoparticles by activated sludge. Chemosphere. 92(5), 524-528 (2013)

41. Yoon, K., Byeon, J.H., Park, J., Hwang, J.: Susceptibility constants of E. coli and Bacillus subtilis to $\mathrm{Ag}$ and $\mathrm{Cu}$ nanoparticles. Sci. Total Environ. 37(3), 572-575 (2007) 